\title{
Anabases
}

ANABASES Traditions et réceptions de l'Antiquité

$17 \mid 2013$

Varia

\section{Hartmut BÖHME, Marco FORMISANO (éd.), War in Words: Transformations of War from Antiquity to Clausewitz}

Yohann Le Tallec

\section{OpenEdition}

Journals

Édition électronique

URL : http://journals.openedition.org/anabases/4255

DOI : 10.4000/anabases.4255

ISSN : 2256-9421

Éditeur

E.R.A.S.M.E.

Édition imprimée

Date de publication : 1 mars 2013

Pagination : 276-278

ISSN : 1774-4296

\section{Référence électronique}

Yohann Le Tallec, « Hartmut вöHme, Marco formisano (éd.), War in Words: Transformations of War from Antiquity to Clausewitz », Anabases [En ligne], 17 | 2013, mis en ligne le 01 avril 2013, consulté le 22 septembre 2020. URL : http://journals.openedition.org/anabases/4255 ; DOI : https://doi.org/ $10.4000 /$ anabases. 4255

Ce document a été généré automatiquement le 22 septembre 2020

(c) Anabases 


\title{
Hartmut BÖHME, Marco FORMISANO (éd.), War in Words: Transformations of War from Antiquity to Clausewitz
}

\author{
Yohann Le Tallec
}

\section{RÉFÉRENCE}

Hartmut BÖHME, Marco FORMISANO (éd.), War in Words : Transformations of War from Antiquity to Clausewitz, Berlin-New York, De Gruyter, 2011, 431 p.

84, 95 euros / ISBN 978-3-11-024541-7.

1 Ce recueil de 18 contributions aborde les relations dialectiques entretenues entre pratiques et théories de la guerre et les façons de les lire, de les écrire et de les comprendre, de l'Antiquité gréco-romaine à la période moderne. Dès l'Antiquité, les rapports étroits entretenus entre guerre et culture furent en effet soulignés par de nombreux philosophes, historiens et hommes de lettres. Pour le philosophe Héraclite d'Éphèse ( $\mathrm{vI}^{\mathrm{e}}$ siècle av. J.-C.), guerres et conflits sont décrits comme pères de toutes choses. Le caractère inévitable de la guerre est également posé par les penseurs grecs et romains. Les Lois de Platon établissent ainsi l'activité guerrière comme un principe intangible de fonctionnement du monde des cités (Lois, 626a). Cette perception de la guerre domine les représentations jusqu'à l'Antiquité tardive. L'écrivain romain Végèce (fin $\mathrm{IV}^{\mathrm{e}}$-début $\mathrm{V}^{\mathrm{e}}$ siècle) décrit ainsi les Spartiates comme « des hommes dignes de la plus haute admiration et estime car ils s'adonnaient à l'art particulier de la guerre sans lequel les autres arts ne pourraient être » (Epitoma re militaris, 3).

2 Un des objets du présent volume est aussi d'identifier les évolutions du discours sur la guerre, d'Hésiode à Clausewitz, en insistant tout particulièrement sur les éléments de continuité à travers lesquels s'élabore une image de l'Antiquité perçue comme un âge exemplaire, standardisé et éternellement valide. De façon paradoxale, les réflexions modernes sur les modèles antiques (principalement les œuvres d'Élien, de Végèce et de 
Léon de Byzance) connurent un fort développement au moment même où des progrès technologiques majeurs (balistiques, armes à feu) inauguraient une transformation radicale des pratiques de la guerre et les rendaient de fait inopérants. Ce paradoxe se retrouve ainsi tout particulièrement dans les réformes militaires initiées par Guillaume $\mathrm{I}^{\mathrm{er}}$ de Nassau, prince d'Orange, à la fin du XVI $\mathrm{I}^{\mathrm{e}}$ siècle, qui se caractérisent par l'influence de la redécouverte de l'art antique de la guerre alliée aux innovations techniques de l'âge moderne. Cette tension entre l'Antiquité, proposée comme norme et modèle, et sa disqualification du fait de l'évolution des pratiques de la guerre à partir de la Renaissance trouve un point d'achèvement avec les travaux du théoricien militaire prussien Carl von Clausewitz (1780-1831). Mais même s'il élabora un style nouveau d'argumentation et proposa une nouvelle conception de la guerre, il est tout à fait caractéristique que ses travaux ne se départirent jamais totalement du caractère normatif imposé par les traités antiques.

$3 \quad$ Les deux directeurs de cette publication rappellent également que les auteurs de traités militaires, qu'ils appartiennent à l'Antiquité ou à la période moderne, s'inscrivent pour la très grande majorité d'entre eux dans une tradition commune caractérisée par une position d'extériorité par rapport à l'expérience vécue. D'un point de vue méthodologique, ce recueil d'articles s'inscrit dans la lignée de l'ouvrage fondateur (encore trop peu connu de l'historiographie française) de John Keegan, The face of the battle (1983), et insiste tout particulièrement sur les perspectives et limitations cognitives communes à ceux qui écrivent sur la guerre (on peut cependant à ce stade regretter qu'aucune des 18 contributions ne porte un regard particulier sur le cas de Thucydide ou de Xénophon, ce dernier pouvant à bon droit apparaître comme un théoricien du fait militaire).

Quatre sections composent ce livre : Judging war s'intéresse aux réflexions sur la guerre et la paix autour de cinq périodes : la Grèce archaïque illustrée par un article de Glenn Most sur les relations entretenues entre guerre et justice dans la Théogonie et Les Travaux et les Jours d'Hésiode, l'Antiquité romaine tardive est illustrée par une contribution de Therese Fuhrer sur saint Augustin, la période moderne par une analyse comparative des théories de Machiavel, Grotius et Gentili par Peter Schröder, enfin, la période contemporaine est abordée par le biais de la contribution de Gian Enrico Rusconi sur l'influence des auteurs antiques dans l'œuvre de Clausewitz. Harriet Zundorfer apporte un éclairage comparatiste intéressant en analysant la perception de la question guerre/justice sous la dynastie Song (960-1279).

La seconde section, Seeing war, traite de la façon de voir la guerre et de la rendre visible, principalement dans les cités italiennes de la Renaissance. La troisième section, Writing war, porte sur la façon d'écrire la guerre. Il est là moins question d'analyser la place de la guerre dans les textes littéraires que de considérer jusqu'à quel point la guerre ellemême devint une des matrices de la littérature. Giusto Traina traite ainsi de la damnatio memoriae dont fait l'objet la bataille de Carrhes dans la littérature impériale (défaite du triumvir Crassus face au général parthe Suréna en 53 av. J.-C.). La contribution de Werner Röcke porte sur la permanence de la perception antique de la guerre dans les ouvrages militaires médiévaux. Enfin, la quatrième section, intitulée War: Techne and Tyche, se clôt sur la contribution d'Hartmut Böhme consacrée à Clausewitz et l'importance de la réception des exempla antiques dans l'élaboration des travaux du théoricien militaire prussien. 


\section{AUTEURS}

\section{YOHANN LE TALLEC}

ANHIMA (UMR 8210)

yletallec@netcourrier.com 